\title{
Application and prospect of a high-resolution remote sensing and geo-information system in estimating earthquake casualties
}

\author{
T. Feng ${ }^{1,2, *}$, Z. Hong ${ }^{3,5, *}$, Q. Fu ${ }^{4}$, S. $\mathrm{Ma}^{2}$, X. Jie ${ }^{2}$, H. Wu ${ }^{1}$, C. Jiang ${ }^{2}$, and X. Tong ${ }^{3}$ \\ ${ }^{1}$ School of Life Sciences and Technology, Tongji University, 1239 Siping Road, Shanghai, 200092, China \\ ${ }^{2}$ Department of Disaster and Emergency Medicine, Eastern Hospital, Tongji University School of Medicine, 150 Jimo Road, \\ Shanghai, 200120, China \\ ${ }^{3}$ College of Surveying and Geo-Informatics, Tongji University, 1239 Siping Road, Shanghai, 200092, China \\ ${ }^{4}$ Research Institute of Structural Engineering and Disaster Reduction, College of Civil Engineering, Tongji University, \\ 1239 Siping Road, Shanghai, 200092, China \\ ${ }^{5}$ College of Information technology, Shanghai Ocean University, 999 Huchenghuan Road, Shanghai, 201306, China \\ *These authors contributed equally to this work.
}

Correspondence to: C. Jiang (jch@tongji.edu.cn) and X. Tong (xhtong@tongji.edu.cn)

Received: 7 November 2013 - Published in Nat. Hazards Earth Syst. Sci. Discuss.: 5 December 2013

Revised: 4 July 2014 - Accepted: 16 July 2014 - Published: 25 August 2014

\begin{abstract}
An accurate estimation of a casualty rate is critical in response to earthquake disasters, and could allow an increase in the survival rate. Building damage is considered to be a major cause of earthquake casualties in developing countries. High-resolution satellite imagery (HRSI) can be used to detect the building damage in a period of a short time. This makes it possible to use a model to estimate earthquake casualties immediately after the occurrence of an earthquake. With respect to the capability of HRSI, this study built a new model for estimating the casualty rate in an earthquake disaster based on remote sensing and a geographical information system. Three groups of earthquake data, the $2003 \mathrm{Bam}$ earthquake, the 2008 Wenchuan earthquake, and the 2010 Yushu earthquake, were used to evaluate this model. The results indicated that our new model significantly improved the accuracy in predicting the casualty rate. The parameters used in the model vary between developed and developing countries. This study could provide valuable information for a more efficient rescue operation in response to earthquakes.
\end{abstract}

\section{Introduction}

The estimation of the casualty rate immediately after an earthquake is becoming more and more necessary, as the increase in the global population is largely concentrated in urban towns and cities (Wyss and Trendafiloski, 2011). In recent years, earthquakes that caused significant damages have occurred frequently all over the world, such as the 2008 Wenchuan earthquake (Burchfiel et al., 2008), the 2009 L'Aquila earthquake (Ameri et al., 2009), the 2010 Chile earthquake (Lay et al., 2010), the 2010 Haiti earthquake (Daniell et al., 2013), the 2010 Yushu earthquake (Ni et al., 2010), the 2011 Great East Japan earthquake (Mimura et al., 2011) and the 2013 Ya' an earthquake (Tang and Zhang, 2013).

Although the prevention of earthquakes is virtually impossible in the foreseeable future, its impact can be mitigated or minimized by proactive risk reduction. There are still a vast number of buildings in developing countries that were not designed to withstand the seismic standard of earthquakes (Kenny, 2012). Building damage is a major contributor to earthquake casualties in many developing countries. In the developed countries, the majority of buildings were designed to withstand earthquakes (Peek-Asa et al., 1998). In Japan for example, secondary disasters such as fire were instead the main contributors to earthquake casualties (Yamazaki et al., 1996).

Casualty estimation is one of the most crucial processes to support the design of a rescue plan. The less time that is used to prepare for the rescue, the more lives can be saved. Many methodologies have been developed to estimate earthquake 
casualties. Anagnostopoulos and Whitman (1977) suggested a method to estimate casualties, which took into account the building type, time of earthquake occurrence and population distribution in their model. However, the application of this model in a real situation was not discussed. Tiedemann (1989) emphasized that the quality of building was a critical factor that affected the casualty rate. The final casualty rate could be calculated from the earthquake intensity, time of earthquake occurrence, season, influence of any warning, and local habits. These factors were also emphasized by Coburn (1994), who compiled a preliminary statistics report. Shiono (1995) built a functional relationship between building collapse rate and fatality rate. He reported on several earthquakes and proposed that the casualty functional relationships of each earthquake were not the same in different earthquakes. In a word, there is no one common model to estimate earthquake casualties around the world.

Due to technical restrictions, predicting earthquake casualties with previous models could only be used to assess loss. They failed to provide any obvious help for earthquake relief. As the informatics techniques were widely used in the early years, real-time prediction of earthquake casualties became feasible. Some researchers used information on local quake intensity to calculate the grade of building damage, and subsequently estimated the casualties (Wyss, 2004; Porter et al., 2008). A framework had been built based on this theory (Jaiswal et al., 2011). Due to the geographic differences, Aghamohammadi et al. (2013) used a machinelearning method to build the casualty estimation mode.

Direct methods have been used to analyze various factors related to the casualty rate (Gutiérrez et al., 2005; Petal, 2011; Wyss and Trendafiloski, 2011). Besides building damage, spatial population distribution and its variations in an earthquake region are factors that influence the casualty rate. An earthquake-prone region with a larger population has a greater potential risk. Furthermore, the issue of spatial and immigration population is not only useful in earthquake relief, but is also critical from a public health and homeland security perspective (Chen, 2002; Dobson et al., 2000; Hay et al., 2005; Sutton et al., 2001). Compared to traditional maps of population distribution, the high-resolution geospatial and temporal maps have proved to be more useful (Bhaduri et al., 2007; Aubrecht et al., 2013). These maps can be used not only in earthquake relief, but also for risk evaluation (Zuccaro and Cacace, 2011; Aubrecht et al., 2012; Freire and Aubrecht, 2012).

Previous studies have contributed greatly to lessening the impacts of an earthquake, but newer techniques were required to help the relief efforts following an earthquake. Earthquakes themselves do not cause deaths; damage from buildings does (Petal, 2011). If the condition of building damage is known immediately after an earthquake, the accuracy of casualty estimation within a short time frame can be improved greatly. High-resolution satellite imagery (HRSI) has recently been used to detect the difference in the height of one building following an earthquake (Teeuw et al., 2013; Lu et al., 2013; Tong et al., 2013; Huang et al., 2013), owing to its large coverage, low cost, short revisit time and adaptable capability of stereo imaging (Tao et al., 2004; Tack et al., 2012).

This paper aimed to build a casualty estimation model based on remote sensing. Compared to other existing methods, the advantages of our proposed model were built from a casualty mechanism rather than from a simple machine learning method (Aghamohammadi et al., 2013) or a fitting method (Feng et al., 2013). Besides a potentially higher accuracy of estimation, a deep analysis of casualty mechanisms in different countries can also be achieved with quantitative evidence. Based on our experience at the scene of an earthquake, it is invaluable to know the change in a survival rate. This change was therefore also discussed in this study, based on our proposed model.

\section{Data and methods}

This model is used to estimate the casualty number immediately after an earthquake, rather than the risk evaluation of an earthquake, and is composed of three parts (Fig. 1). In the first part, high-resolution satellite images (HRSIs) covering the affected area were collected. In the ideal situation, the damage index (DI) of one building was calculated using the change in height in pixels of the building before and after the earthquake. Because of reasons such as image resolution, other alternative methods, including visual interpretation (Shalaby and Tateishi, 2007) and automatic interpretation (Benz et al., 2004), were also appropriate. The materials or structure of buildings also have a strong impact on earthquake casualty. Therefore, in the second part of our model, the building attributes including materials and structure were collected from a local geographic information database, which was supplied by the local information management center, and used to calculate the materials and structure index (MSI) of buildings. In the third and final part, a casualty estimation model based on MSI and DI was proposed. To evaluate the model, three sets of earthquake data were used. The entire process is described in the following subsections.

\subsection{Data}

The three data sets in this study, the 2003 Bam, 2008 Wenchuan, and 2010 Yushu earthquakes (Fig. 2), were used to evaluate our model.

The 2003 Bam earthquake measured 6.6 M and occurred at 05:27 LT on 26 December 2003. Its epicenter was at a depth of $10 \mathrm{~km}$ and was located at $29^{\circ} 6^{\prime} \mathrm{N}$ and $58^{\circ} 17^{\prime} \mathrm{E}$ near the city of Bam, $180 \mathrm{~km}$ southeast of the provincial capital of Kerman and $975 \mathrm{~km}$ southeast of Tehran. At least 26271 and 30000 people were reported killed and injured, 


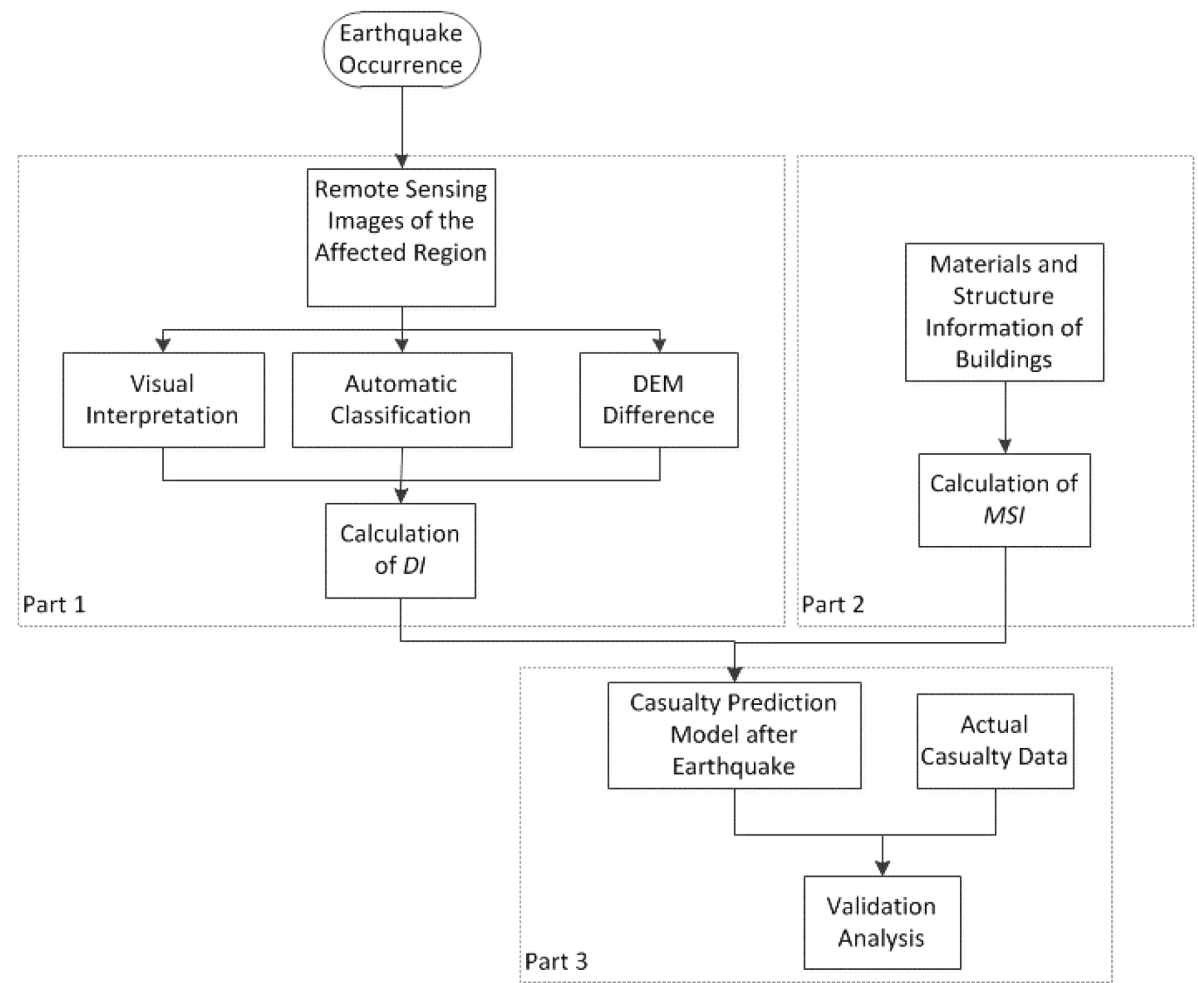

Figure 1. Framework of earthquake casualty estimation.

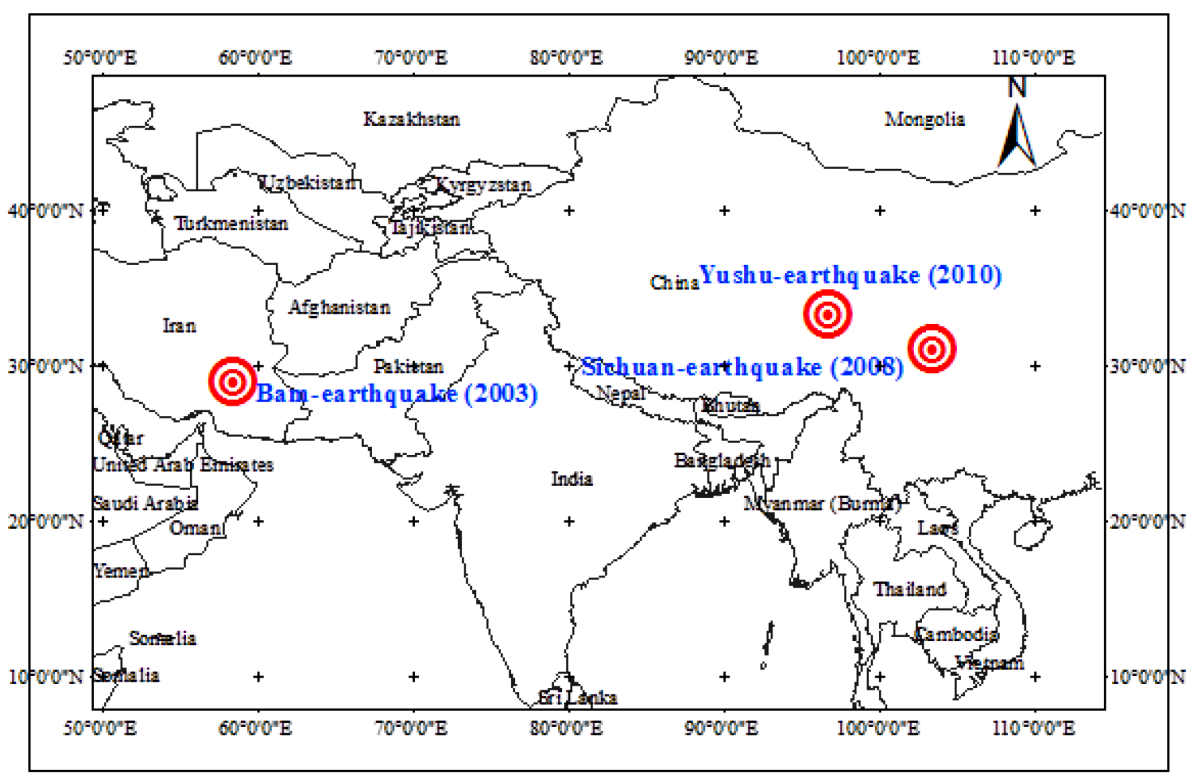

Figure 2. Study areas.

respectively (USGS, 2003). One part of Bam, as described in Aghamohammadi et al. (2013), was selected as the study area. The detailed casualty number, as well as the number and type of damaged buildings, has been reported (Kuwata et al., 2005). According to their report, the actual casualty number in this study area was 21924 . The data reported by
Kuwata et al. (2005) were prepared by the Iranian government. The method of data collection was similar to that of visual interpretation. The HRSI collected was QuickBird imagery with a spatial resolution of around $0.7 \mathrm{~m}$ (Fig. 3). The image was downloaded from imagery courtesy of DigitalGlobe (http://www.digitalglobe.com). 

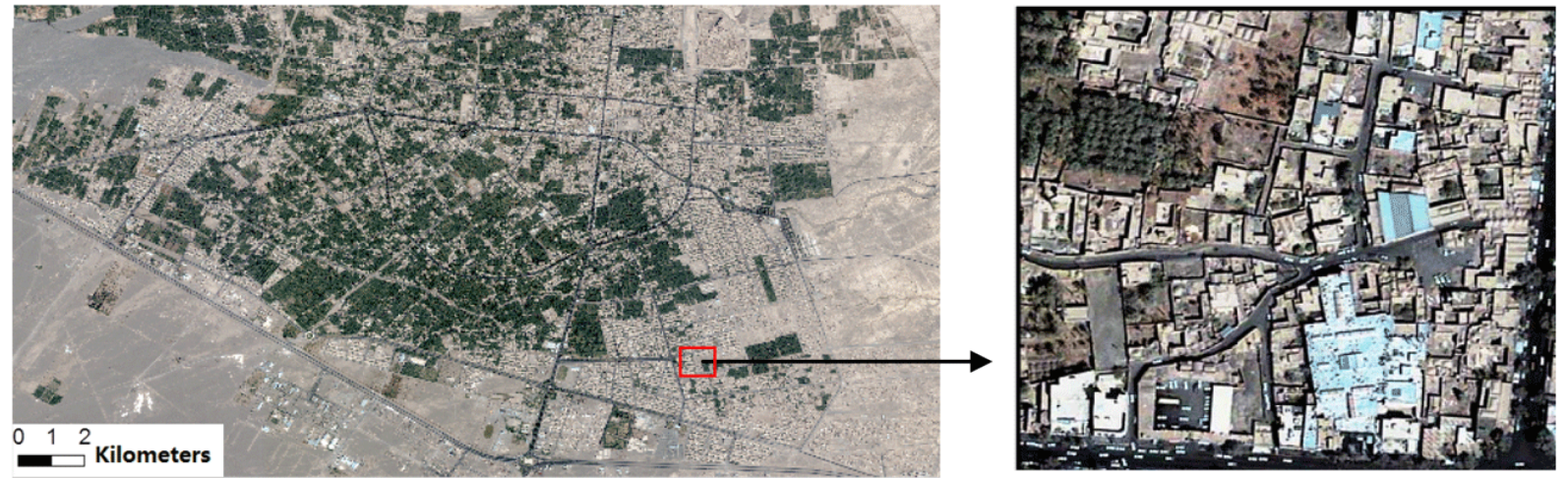

(a)

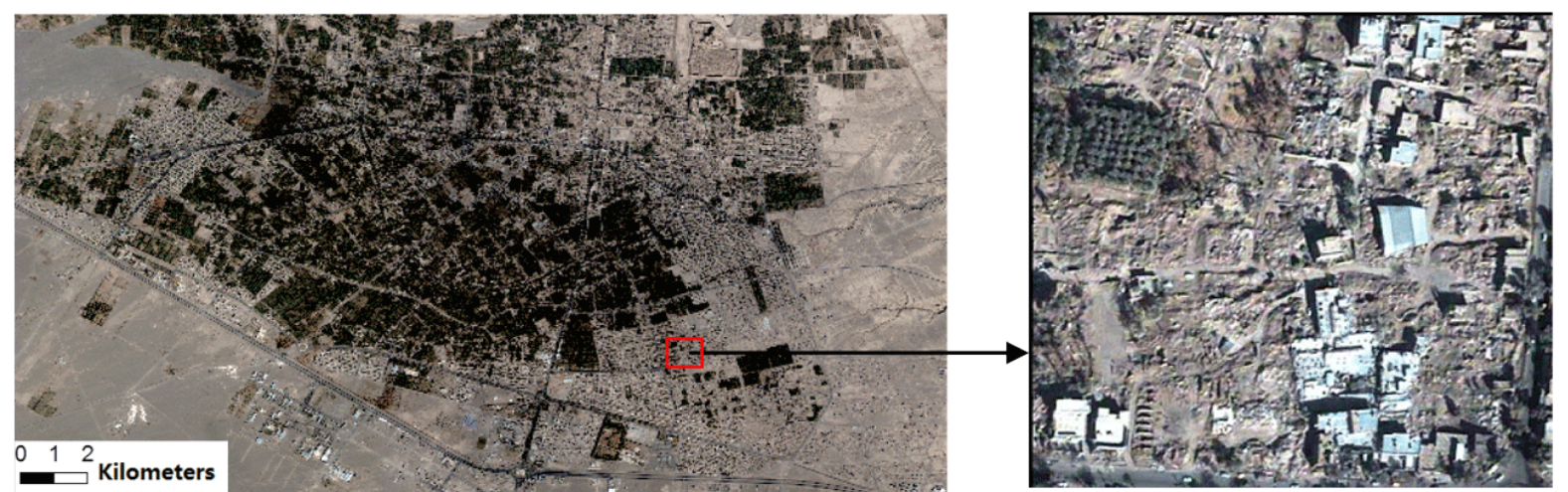

(b)

Figure 3. Pre- and post-seismic QuickBird images of the Bam earthquake.

The magnitude of the 2008 Wenchuan earthquake that occurred at 14:28 LT on 12 May 2008 was $7.9 \mathrm{M}$. The epicenter was at $31^{\circ} 11^{\prime} \mathrm{N}$ and $103^{\circ} 22^{\prime} \mathrm{E}$, and the focal depth was $19 \mathrm{~km}$ (Stone, 2008). The official documents reported that $\sim 15$ million people were affected by the earthquake, including $\sim 70000$ people killed, $>370000$ people injured, and $>17000$ people missing. One of the affected cities, Dujiangyan, was selected as the research area. According to the statistical data obtained from the local documents, 3091 people were killed and 10560 people were injured in Dujiangyan. The HRSI used in this earthquake was one pair of post-earthquake IKONOS images (with a $97.97 \%$ overlap area) to detect the damaged area (Fig. 4). Sixtytwo ground points were surveyed by the Global Positioning System (GPS), and their accuracy was better than $5 \mathrm{~cm}$. The $1: 500$ scale digital topographic map of Dujiangyan was used to build the pre-earthquake digital surface models (DSMs).

The 2010 Yushu earthquake occurred at 07:49 LT on 14 April 2010, and the magnitude was 7.1 M. The epicenter of the 2010 Yushu earthquake was located at $33^{\circ} 12^{\prime} \mathrm{N}$, $96^{\circ} 36^{\prime} \mathrm{E}$, at a focal depth of $14 \mathrm{~km}$ (Guo et al., 2010). In this earthquake, 2968 people were killed and 12135 people were injured. Jiegu, which is in the center of Yushu, was severely affected, and was selected as the study area. In the affected area of Jiegu, 1942 people were killed and 8283 people were injured. The HRSIs were collected by QuickBird with $0.7 \mathrm{~m}$ spatial resolution (Fig. 5). The image was downloaded from imagery courtesy of DigitalGlobe (http://www.digitalglobe.com).

In this study, the areas were less developed. The highresolution geospatial and temporal map was unavailable. Compared to metropolitan areas such as Beijing and Shanghai, the regions in this study were relatively secluded, and the condition of personnel mobility was low. In contrast to the study area in the Wenchuan earthquake, nearly all residents in the other two earthquake events were in their houses or apartments. To minimize the prediction error, the buildings were classified according to their DI and MSI. Next, the casualties were calculated based on the sum of different types of buildings, rather than for each building. Therefore, the local statistical data can be referred to in this study. 

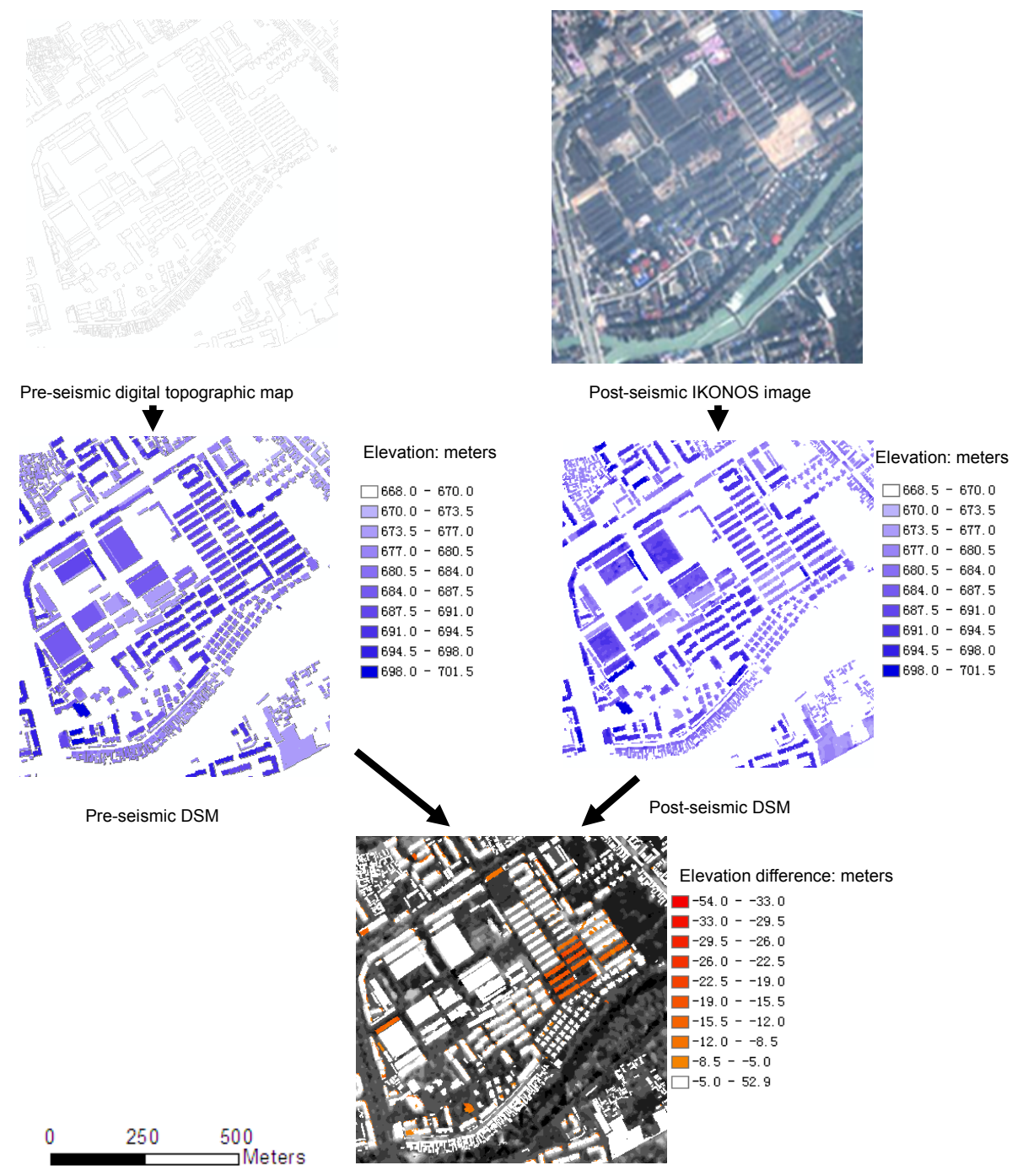

DSM difference

Figure 4. Three-dimensional detection of building damage by using DSM difference.

\subsection{Methods}

\subsubsection{Damage detection}

The damage level of one building can be classified into five groups based on a field survey (Yano et al., 2004; Barbat et al., 2008), as shown in Table 1. However, it remains a challenge for damage detection by remote sensing. Kerle (2010) illustrated the difficulty of image-based damage assessment. In 2011 and 2013, Gerke and Kerle (2011) and Kerle and Hoffman (2013) further illuminated the challenge of distinguishing different EMS98 levels using HRSI. Based on the three reports of Wang et al. (2013), Hisada et al. (2005) and Yamazaki et al. (2005), the kappa value between field survey and HRSI was increased from 0.2 to 0.55 when the damage condition of a building was clustered into three groups rather than five groups. D5 and D4 belong to two groups. The damage grade values less than D4 were grouped. The four types of damage conditions could not be distinguished using HRSI. Regarding casualty estimation, the damaged buildings belonging to the D4 and D5 groups were the major determinants of injury and mortality in earthquakes in developing countries. The factors causing the casualties in the other classifications of damaged buildings vary significantly, and some casualties were not caused by the building damage. This situation occurred more in developed countries. Without detailed epidemiological statistics, the regularity of casualties from the D1 to D3 buildings was difficult to sum up. Therefore, this study only focused on the D4 and D5 buildings, and used the method reported by Tong et al. (2012), including visual interpretation (Gamba and Casciati, 1998; Saito et al., 2004), automatic classification (Turker and Sumer, 2008), and DSM differences (Turker and Cetinkaya, 2005) 


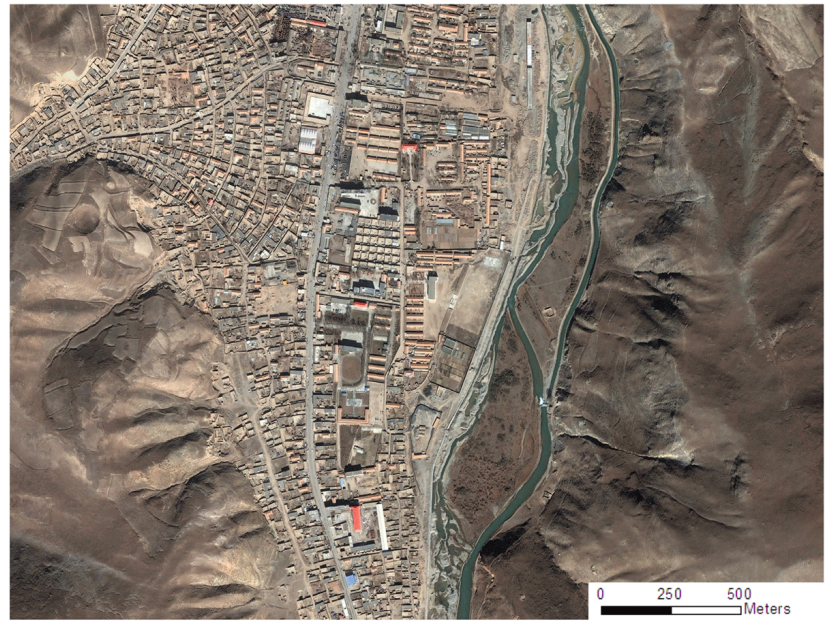

(a)

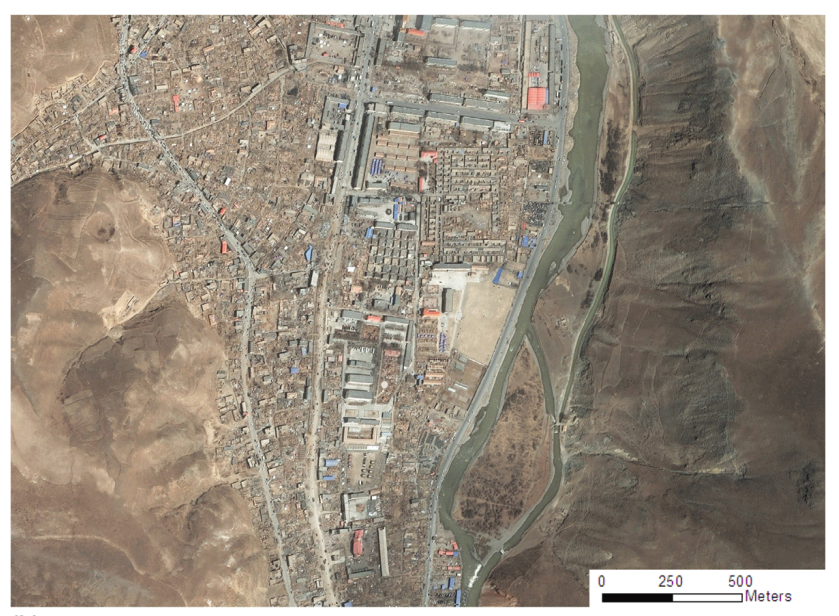

(b)

Figure 5. Pre- and post-seismic QuickBird images of the Yushu earthquake.

to evaluate the damage grade. The visual interpretation is a direct method for assessing the damaged condition of buildings from two-dimensional (2-D) remote sensing images. Although this method has a high accuracy, it requires more time. The automatic classification based on the spectral band and textural feature of buildings utilizes diverse information tools to assess the damaged condition of buildings. The DSM difference was a new method with a high accuracy. In the first step, the pre-earthquake DSM was generated by a point cloud (Ma, 2005), which was marked on the digital topographic map when the resolution of images prior to the earthquake was not high enough to generate the DSM. Otherwise, the pre-earthquake DSM was generated by stereo images (Tong et al., 2012; Feng et al., 2013). The post-earthquake DSM should be generated by stereo images because the digital topographic map post earthquake cannot be obtained. From the height change of points belonging to the same DSM between pre- and post-earthquake, the damage grade of one building was calculated. When the decrease in nearly all the points of one building was larger than $80 \%$, the building belonged to D5. When the decrease in some points of one building was between 60 and $80 \%$, the building belonged to D4. The DI values were calculated using Eq. (1):

$\mathrm{DI}=\frac{\sum_{i=1}^{n} \frac{h c_{i}}{h_{i}}}{n}$,

where $h_{i}$ is the pre-event height of a point on a building and $h c_{i}$ is the height of a point after a earthquake.

\subsubsection{Relationship between casualty and building attributes}

In our previous study (Feng et al., 2013), we assumed that the structure and materials of buildings were significantly related to the corresponding earthquake casualty. When people in rooms felt the earthquake, they started running for the exits, which grew to become a stream of people. A good building structure can increase the velocity of the stream flow and expose fewer people to suffering from building damage. The velocity of the stream is also affected by the number of people in the stream. The escaping rate is expressed as follows:

$r_{\mathrm{e}}=\frac{v t}{N(T ; X)}$,

where $v$ is the velocity of the people stream, $t$ is the available time to escape, and $N$ is the usual number of people in the building. $N$ is a dependent variable, and changes with time and other factors $(X)$ such as place and weather. This variable $(N)$ is complex, and many studies have been conducted regarding the distribution and change in the number of people (Aubrecht et al., 2009, 2010a, b). $v$ is the dependent variable of the function, and is affected by the features of the structure, such as the number of stairs, corridor width, stair width, pedestrians in the corridor, and the strength of the stairs. The interval of the independent variable $t$ is from the time $\left(t_{0}\right)$ at which people felt the shake of an earthquake to the time $\left(t_{1}\right)$ at which the shake stopped.

After the occurrence of earthquake people who were still in the building suffered from building damage, mainly from falling objects. Small falling objects can only injure people, while big falling objects can trap people, even causing death. The key factor that helped the trapped people to survive was whether there was still a survival space (Macintyre et al., 2011) in the damaged building. The death rates of different buildings after collapse are shown in Fig. 6 (Feng et al., 2013). We denoted the death rate as $C_{\max }$.

In general, 40-60\% of trapped people in the collapsed buildings died at once. The number of deaths stabilized after $72 \mathrm{~h}$ (Yu et al., 2013). The people buried under woodenframe buildings had more survival space than those buried under adobe or brick masonry buildings; therefore, more 
Table 1. Damage index and classification of damage to masonry buildings (EMS98).

\begin{tabular}{lll}
\hline $\begin{array}{l}\text { Damage } \\
\text { grade }\end{array}$ & Damage description & Damage condition \\
\hline D1 & Negligible to slight damage & $\begin{array}{l}\text { Hairline cracks in very few walls; fall of small pieces of plaster only; fall of loose stones } \\
\text { from upper parts of buildings in a very few cases. }\end{array}$ \\
\hline D2 & Moderate damage & Cracks in many walls; fall of large pieces of plaster; partial collapse of chimneys. \\
\hline D3 & Substantial to heavy damage & $\begin{array}{l}\text { Large and extensive cracks in most walls; roof tiles detached; chimneys fractured at the } \\
\text { roofline; failure of individual non-structural elements (partitions, gable walls). }\end{array}$ \\
\hline D4 & Very heavy damage & Partial structural failure of roofs and floors; serious failure of walls. \\
\hline D5 & Destruction & Near total or total collapse. \\
\hline
\end{tabular}

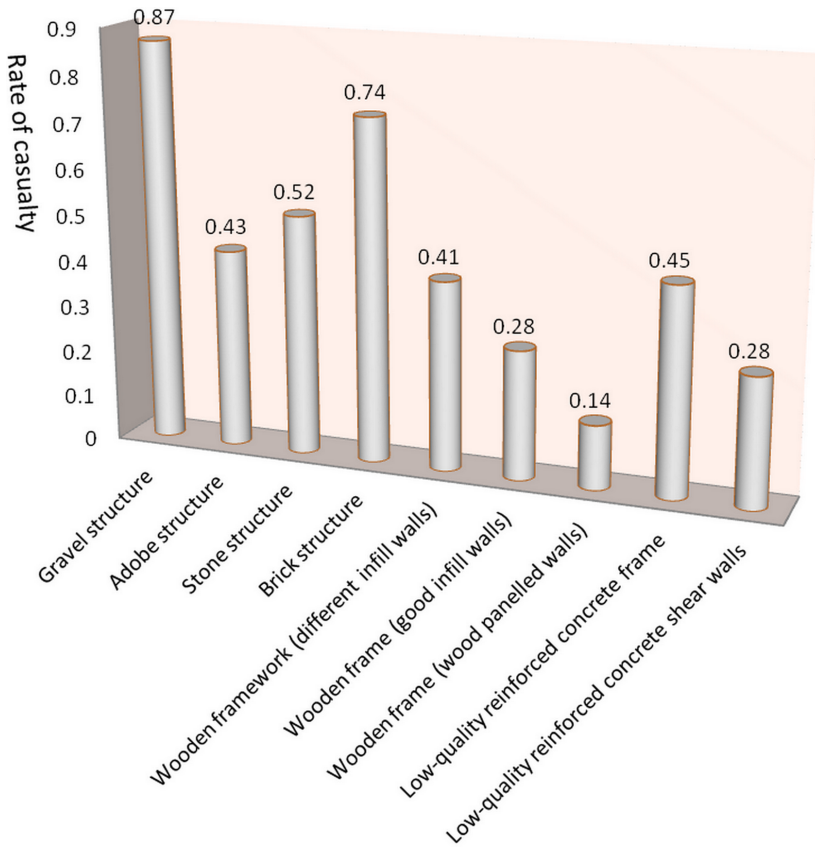

Figure 6. Death rate in collapsed buildings by different materials.

trapped people may be still alive in wooden-frame buildings. The principle can be described as follows:

$\frac{\mathrm{d} N_{\mathrm{s}}}{\mathrm{d} t}=-N_{\mathrm{s}} r$,

where $N_{\mathrm{s}}$ is the number of people still alive in damaged buildings and $r$ is the scale factor that changes with the building materials. Therefore, $N_{\mathrm{s}}(t)=N_{\mathrm{S}}\left(t_{1}\right) e^{-r\left(t-t_{1}\right)}$, where $N_{\mathrm{s}}\left(t_{1}\right)$ is the initial number of trapped people who are still alive.

By combining Eqs. (2) and (3), the MSI can be expressed as follows:

$\operatorname{Ln}(\mathrm{MSI})=\operatorname{Ln}\left(\frac{N(T ; X)-v t_{1}}{N(T ; X)}\right)-r\left(t_{2}-t_{1}\right)$, where $t_{2}$ is the time at which the possibility of survival is nearly none. Usually, this time is $72 \mathrm{~h}$. Each type of building has a special MSI. $v$ and $r$ values are different for each type of building. Using Eq. (4), we can obtain

$$
\begin{aligned}
D & \cdot e^{\operatorname{Ln}\left(\frac{N(T ; X)-v t_{1}}{N(T ; X)}\right)-r\left(t_{2}-t_{1}\right)}=D \cdot\left(\frac{N(T ; X)-v t_{1}}{N(T ; X)}\right) \\
& \cdot e^{-r\left(t_{2}-t_{1}\right)}=1-C,
\end{aligned}
$$

where $\left(\frac{N(T ; X)-v t_{1}}{N(T ; X)}\right)$ is the living rate of people still trapped in the damaged buildings, equal to $N_{\mathrm{s}}\left(t_{1}\right), D$ is a parameter related to DI and other factors except structures and materials, $e^{-r\left(t_{2}-t_{1}\right)}$ is the change rate of survivals from $t_{1}$ to $t_{2}$, and $1-C$ is the survival rate. $C$ is the final casualty rate.

\subsubsection{Other factors}

Besides the damage grades and attributes of buildings, other factors known as software indices, such as the time when an earthquake occurred, the educational level of the local residents, the amount of training received in earthquake escape, and the economic level, were evaluated in this study.

\subsubsection{Casualty prediction model}

Because the relationship between the damage grade of one building and the casualty number is not a linear function, we did not use the DI to replace the $D$ in Eq. (5) directly. The relationship between damage grade and casualty number can be expressed as $\frac{\mathrm{d} C}{\mathrm{dDI}}=\mathrm{DI} \cdot s$, where $s$ is the scale factor. Then, $C=\frac{1}{2} s \mathrm{DI}^{2}$ for $C\left(\mathrm{DI}_{0}\right)=0$. Based on the earlier numerical simulation results (Feng et al., 2013), we changed $C=\frac{1}{2} s \mathrm{DI}^{2}$ into

$C=e^{2 \operatorname{Ln} \frac{1}{2}(\mathrm{DI})+\operatorname{Ln}(s)}$.

By combining Eqs. (5) and (6), we proposed a casualty prediction model as follows:

$C=1-e^{a \operatorname{Ln}(\mathrm{DI})+b \operatorname{Ln}(\mathrm{MSI})+c}$.

The estimated number of casualties is then $N(T ; X) \cdot C$. 


\section{Results and discussion}

In this section, we provided not only the numerical experimental results of the three earthquakes, but also the explanation of the entire process from the beginning to the end. The process included the acquisition of crucial data, transformation of the data into the expression according to the criterion of the model, and solving and evaluation of the model.

\subsection{Essential data and model solving}

To estimate the casualty number in a short period of time after an earthquake, this study required data regarding damaged buildings, the material and structure of damaged buildings, and the distribution of residents in damaged buildings. Using a pair of HRSIs of the post-earthquake and the point clouds marked on the digital topographic map of Dujiangyan, we calculated the height difference of each point on each building. The DI of each building was calculated using Eq. (1). To reduce the error, we did not estimate the casualties in one building, but rather estimated the casualties in a group of buildings under similar conditions. In the case of Dujiangyan, the damaged buildings were classified into six categories. We denoted each category by one letter and two subscript letters. For instance, $N_{a c}$ indicates the number of collapsed buildings of type A. The other five types of buildings were damaged type A buildings $\left(N_{\mathrm{ad}}\right)$, collapsed type $\mathrm{B}$ buildings $\left(N_{\mathrm{bc}}\right)$, damaged type B buildings $\left(N_{\mathrm{bd}}\right)$, collapsed type $\mathrm{C}$ buildings $\left(N_{\mathrm{cc}}\right)$, and damaged type $\mathrm{C}$ buildings $\left(N_{\mathrm{cd}}\right)$. Type A buildings were built using either entirely wood or bricks and wood. Most of them did not follow seismic design principles. This type of building had a similar structure as wooden-frame buildings. Compared to the other types, the casualty rate of type A buildings was lower. Type B buildings were built using unbound aggregate materials without seismic design principles. Once they collapsed, there was nearly no survival space. Therefore, the casualty rate of collapsed type B buildings was very high. This type of building had a similar structure as an unbound aggregate structure. Type C buildings, with a structure similar to low-quality reinforced concrete shear walls, were seismically designed, and the casualty rate of these buildings was very low. After combining the distribution of damaged buildings calculated from remote sensing with the distribution of different structures and materials of buildings in the local GIS database, the available information was expressed mathematically. As one of the severely affected regions in Dujiangyan, the description of Guankou was as follows: $N_{\mathrm{a}}: N_{\mathrm{b}}=3: 7, N_{\mathrm{ac}}: N_{\mathrm{ad}}=7: 3$ and $N_{\mathrm{bc}}: N_{\mathrm{bd}}=4: 6$. Thus, $N_{\mathrm{ac}}: N_{\mathrm{ad}}: N_{\mathrm{bc}}: N_{\mathrm{bd}}=21: 9: 28: 42$. Because the number of occupants has a high correlation with the number of buildings, the approximate distribution of occupants in each type of building was expressed as follows: $R_{\mathrm{ac}}: R_{\mathrm{ad}}: R_{\mathrm{bc}}: R_{\mathrm{bd}}=21: 9: 28: 42$. The casualty number in Guankou was reported to be $\sim 3366$ (Xu et al., 2012).
Therefore, $\quad R_{\mathrm{ac}} \times C_{\mathrm{ac}}+R_{\mathrm{ad}} \times C_{\mathrm{ad}}+R_{\mathrm{bc}} \times C_{\mathrm{bc}}+R_{\mathrm{bd}} \times$ $C_{\mathrm{bd}}=3366$, where $C_{* *}$ is the casualty rate of one type of building. The same subscript letters in this paper have the same meaning. From the local survey report, we calculated $R_{\mathrm{bc}} \times C_{\mathrm{bc}}: R_{\mathrm{bd}} \times C_{\mathrm{bd}}=5: 1$ and $R_{\mathrm{ad}} \times C_{\mathrm{ad}}: R_{\mathrm{bd}} \times C_{\mathrm{bd}}=2: 3$. Thus,

$C_{\mathrm{ac}}: C_{\mathrm{ad}}: C_{\mathrm{bc}}: C_{\mathrm{bd}}=96: 56: 135: 18$.

Then, $21 v \times 96 k+9 v \times 56 k+28 v \times 135 k+42 v \times 18 k$ $=3366$. The $C_{* *}$ values were less than 1 . We therefore made $C_{\mathrm{bc}}$ equal to 0.98 when $k=0.0073$ and $v=65.4$. Here, $v$ represents the percentage of affected people in one unit of affected area. Then, $C_{\mathrm{ac}}=0.71, C_{\mathrm{ad}}=0.41, C_{\mathrm{bc}}=0.98$, and $C_{\text {bd }}=0.13$.

To calculate the parameters of Eq. (7), the values of DI and MSI need to be calculated. According to Eq. (1), the DI values of most of the collapsed buildings were $\sim 0.9$. Because the damaged buildings were grouped together, we set DI equal to 0.9 when the buildings collapsed and DI equal to 0.7 when the buildings were damaged severely. The parameters of Eq. (4) were not easy to determine. Because $\left(\frac{N-v t_{1}}{N}\right)$ was slightly related to the damage grades of buildings besides the materials of buildings, and because $e^{-r\left(t_{2}-t_{1}\right)}$ was related to $C_{\max }$, we proposed a functional relationship as follows:

$\mathrm{MSI}=-1.63 e^{\mathrm{DI}}+0.015 e^{C_{\max }}+5.12$,

with the adjusted $R$ square value of 0.99 , a $p$ value of 0.021 , and a root mean square (rms) error of 0.001. Using this function, $\mathrm{MSI}_{\mathrm{ac}}=0.14, \mathrm{MSI}_{\mathrm{ad}}=0.62, \mathrm{MSI}_{\mathrm{bc}}=0.12$, and $\mathrm{MSI}_{\mathrm{bd}}=0.63$. Combining Eq. (7), DI, and MSI, the model was expressed as follows:

$C=1-e^{100 \mathrm{Ln}(\mathrm{DI})+17.4 \operatorname{Ln}(\mathrm{MSI})+43.6}$,

where the adjusted $R$ square is $0.998, p=0.026$, and $\mathrm{rms}=0.006$. Using Eq. (10),

$$
\begin{aligned}
C_{\mathrm{sum}} & =v \times\left(R_{\mathrm{ac}} \times C_{\mathrm{ac}}+R_{\mathrm{ad}} \times C_{\mathrm{ad}}+R_{\mathrm{bc}} \times C_{\mathrm{bc}}\right. \\
& \left.+R_{\mathrm{bd}} \times C_{\mathrm{bd}}\right) .
\end{aligned}
$$

The predicted and actual casualties are listed in Table 2 . The maximum error between the predicted and actual result was 0.25 . From the viewpoint of rescue, this information is invaluable.

To estimate the number of casualties using our model, two pairs of HRSI covering the affected area were collected before and after the earthquakes. In some situations, the resolution of pre-earthquake satellite images was not high enough to generate the DSMs. Instead, the digital map covered by point clouds can be used to generalize the DSMs prior to an earthquake. The DI of damaged buildings was calculated using the two corrections of coordinates. If both the resolutions of pre-earthquake and post-earthquake satellite images were not high enough to build a DSM, the visual interpretation and 
Table 2. Estimating casualties and the actual casualties.

\begin{tabular}{llrlc}
\hline & Actual & Prediction & Error \\
\hline \multirow{5}{*}{ Guankou } & Collapsed type A & 975 & 964.1 & 0.01 \\
& Damaged type A & 241 & 199.1 & 0.21 \\
& Collapsed type B & 1795 & 1778.6 & 0.01 \\
& Damaged type B & 357 & 352.5 & 0.01 \\
Total & 3368 & 3294 & 0.02 \\
Xingfu & 2846 & 3545 & 0.25 \\
Xujia & 383 & 447 & 0.17 \\
Mean & & & 0.10 \\
\hline
\end{tabular}

automatic classification methods were the alternatives. The attributes of each damaged building were determined from the local GIS database through the coordination of the damaged buildings. After clustering different types of buildings in terms of damaged grade and attributes, the distributions of all types of buildings were calculated. The DI and MSI of each type of damaged building were calculated using Eqs. (1) and (8), respectively, and the value of $C^{* *}$ was calculated using Eq. (9). With the segmentation scales of the distribution of all types of buildings, the number of occupants per scale unit was confirmed. In the case of the Wenchuan earthquake, the number of occupants per scale unit was 64.5. At this time, the casualties could be estimated using Eq. (10). In extreme situations, only HRSI was available. The distribution of buildings with different structures and materials could be deduced from the region where the geographical feature was similar to that of the affected region. The structure and material distribution of buildings belonging to collapsed or damaged groups were theorized from the historical data. The casualty counts estimated using the deduced information could be limited to the first order of error.

\subsection{Application of the model}

To evaluate the practicality of this model, we also applied this model to two other earthquakes: the 2010 Yushu and 2003 Bam earthquakes.

The majority of the casualties of the Yushu earthquake occurred in Jiegu. The building structure in Jiegu is composed mainly of two types, that is, the unbound aggregate structures and the stone structures. The unbound aggregate structures and the stone structures were represented as type $\mathrm{A}$ and type $\mathrm{B}$, respectively. Using the automatic classification method, the distribution of buildings was in the following scale, as it was in the case of Dujiangyan: $R_{\mathrm{ac}}: R_{\mathrm{ad}}: R_{\mathrm{bc}}: R_{\mathrm{bd}}=45: 5: 35: 16$. In the scale, $v=65.4$. From Fig. 2, the MSIs of these four types of damage buildings were calculated: $\mathrm{MSI}_{\mathrm{ac}}=0.95, \mathrm{MSI}_{\mathrm{ad}}=0.32$, $\mathrm{MSI}_{\mathrm{bc}}=0.88$, and $\mathrm{MSI}_{\mathrm{bc}}=0.25$. Furthermore, $\mathrm{DI}_{\mathrm{ac}}=0.90$, $\mathrm{DI}_{\mathrm{ad}}=0.70, \quad \mathrm{DI}_{\mathrm{bc}}=0.90, \quad$ and $\quad \mathrm{DI}_{\mathrm{bd}}=0.70$. Because Jiegu is the center of Yushu, the population density is $\sim 2$ times higher than the town of Dujiangyan. Therefore, $C_{\mathrm{sum}}=2 \times v \times\left(R_{\mathrm{ac}} \times C_{\mathrm{ac}}+R_{\mathrm{ad}} \times C_{\mathrm{ad}}+R_{\mathrm{bc}} \times C_{\mathrm{bc}}+R_{\mathrm{bd}}\right.$ $\left.\times C_{\mathrm{bd}}\right)$. The estimated result was 10302 , while the actual casualty number reported was 10269 , an error of $0.03 \%$.

The Bam earthquake occurred in a populated area. The population density was $\sim 4$ times higher than in Dujiangyan. Most of the buildings in the Bam areas were not seismically designed. The older buildings with non-reinforced masonry were expected to suffer because their masonry structures were heavy, brittle, and vulnerable to quakes in the event of an earthquake. In this case, we referred to them as type A buildings, similar to unbound aggregate structures. A small percentage of buildings had low-quality reinforced concrete frames. We referred to them as type B buildings. Using the visual interpretation method, the distribution of an affected area reported by Kuwata et al. (2005) was on the same scale as was the case for Dujiangyan.

$R_{\mathrm{ac}}: R_{\mathrm{bc}}: R_{\mathrm{ad}}: R_{\mathrm{bd}}=83: 4: 2: 11 ;$ moreover, $\mathrm{MSI}_{\mathrm{ac}}=$ $0.95, \mathrm{MSI}_{\mathrm{ad}}=0.32, \mathrm{MSI}_{\mathrm{bc}}=0.85$, and $\mathrm{MSI}_{\mathrm{bc}}=0.22$. Furthermore, $\mathrm{DI}_{\mathrm{ac}}=0.90, \mathrm{DI}_{\mathrm{ad}}=0.70, \mathrm{DI}_{\mathrm{bc}}=0.90$, and $\mathrm{DI}_{\mathrm{bd}}=$ 0.70. Then, $C_{\text {sum }}=4 \times v \times\left(R_{\mathrm{ac}} \times C_{\mathrm{ac}}+R_{\mathrm{ad}} \times C_{\mathrm{ad}}+R_{\mathrm{bc}}\right.$ $\left.\times C_{\mathrm{bc}}+R_{\mathrm{bd}} \times C_{\mathrm{bd}}\right)$. The estimated result was 22060 , while the actual casualty number was 21924 , an error of $<1 \%$.

The predicted accuracies of the Bam and Yushu earthquakes were higher than the result of the Wenchuan earthquake. Besides the effectiveness of the model, the time of day when the earthquake occurred was also critical. When the Bam and Yushu earthquakes occurred, most of the people were still in their homes, whereas a higher percentage of people may have stayed outside when the Wenchuan earthquake occurred. The predicted results of casualties in Xinfu and Xujia were more than the actual counts. Because of the limitation of the local economic level, high-resolution geospatial and temporal maps required a longer time to build. To combat this problem, a correction parameter was added to our model. Based on a routine number of people, the correction parameter of an area became larger when the number of people increased. When the number of people decreased, the correction parameter became smaller. In the case of Dujiangyan, when the correction parameter was set equal to 0.9 , the predicting error was less than $4 \%$. However, building the geospatial and temporal maps is still essential. Less costly and better energy-saving methods should be developed to enhance these processes.

\subsection{Change in survival rate}

At a real disaster site, the casualty rate increased for 3 or 4 days after an earthquake occurred. Rescue efforts could reduce the amount of casualties. However, the change in the survival rate of each type of building was different. During the time of the earthquake, $\sim 40$ to $\sim 60 \%$ of the people were killed or severely injured in a very short period of time. The rate varied, depending on the attributes and damage grade of buildings. The survival rate decreased with time. Using the value of the final casualty rate calculated by Eq. (5), the changes in the survival rates of different buildings in the 

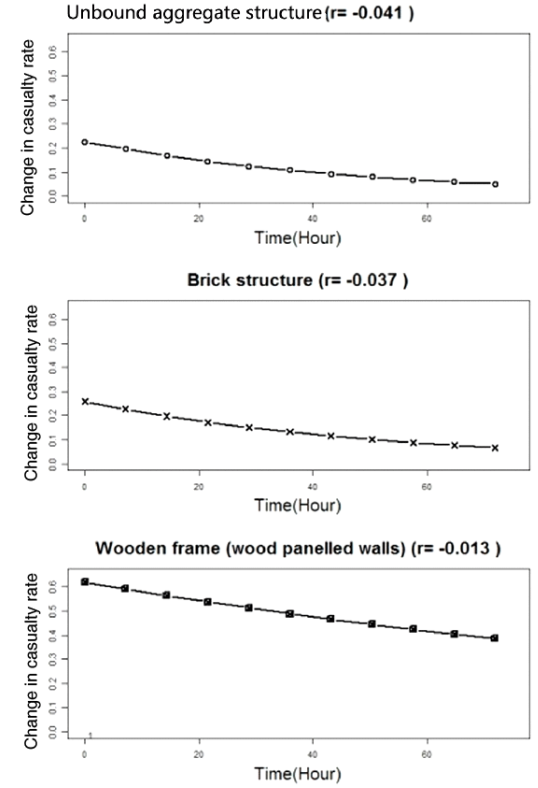

Figure 7. Change in the survival rate of different buildings in a collapsed state.
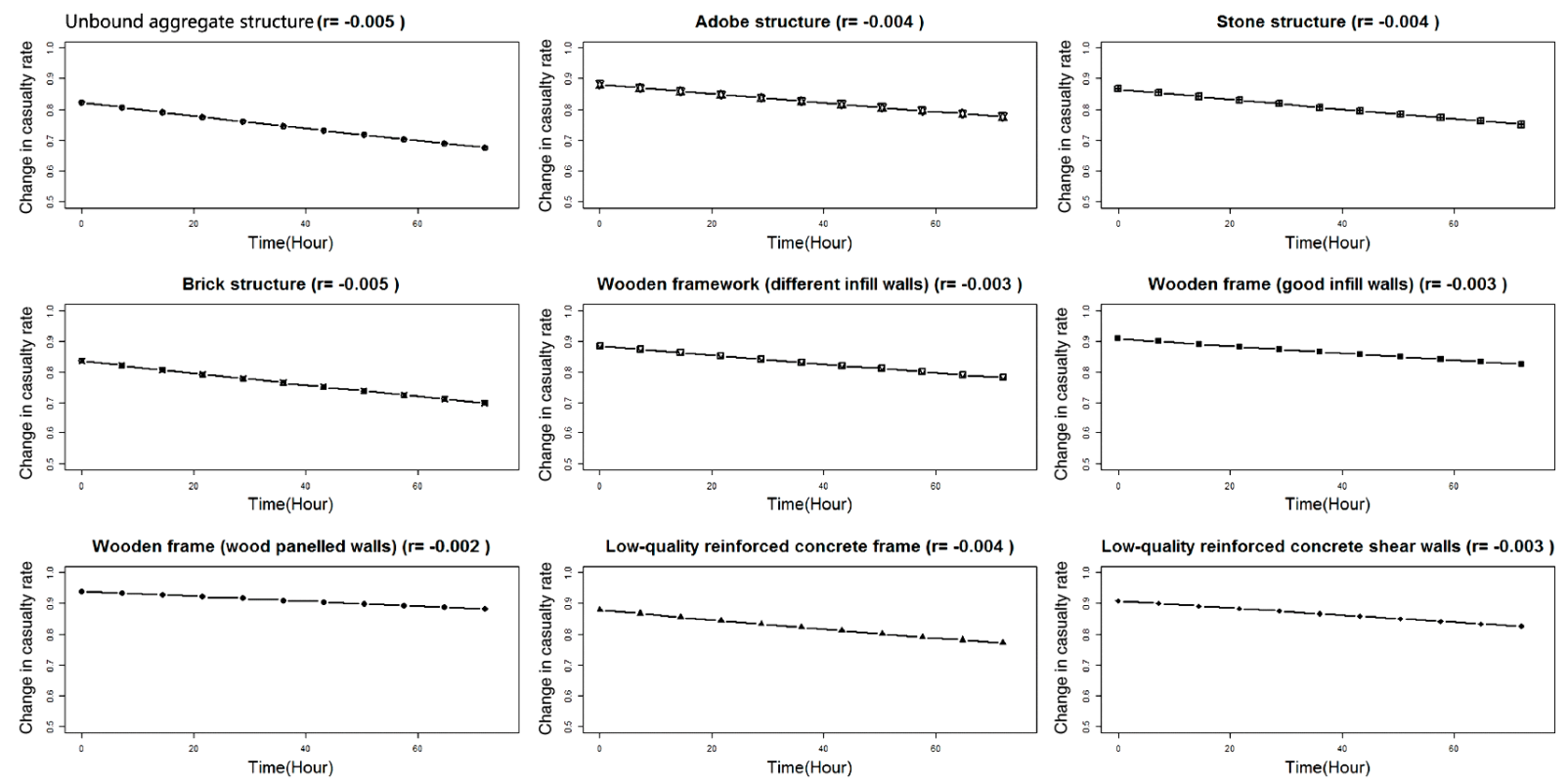

Figure 8. Change in the survival rate of different buildings in a damaged state.

collapsed and damaged states are shown in Figs. 7 and 8, respectively. When the buildings collapsed, the change in the survival rate of each type of building was very different. For example, the survival rate of unbound aggregate structure buildings remained at a low level from the beginning, while the survival rate of wooden framework buildings with different infill walls remained at a relatively high level. Under the limitation of quake relief materials and personnel in the disaster areas, the change in the survival rate of each type of collapsed building should be considered when administrators design the rescue plan. When the buildings were in the damaged state, the change in the survival rate of each type of building was nearly similar, and the survival rate remained at a high level. Although some occupants could not escape from the buildings when the earthquake occurred, they may still have been unharmed. After the quakes passed, many occupants who were relatively unhurt could save themselves by their own effort. Compared to other factors, such as traffic accessability, the areas filled with damaged buildings had a lower weighted value. The change in the survival of buildings 
Table 3. Comparison of different methods.

\begin{tabular}{llll}
\hline Method & Time used $^{1}$ & Case involved & Error rate \\
\hline Aghamohammidi et al. (2013) & More than 1 week & One case & $2.1 \%$ \\
Coburn (1994) & More than 1 week & More than five cases & $32 \%$ \\
Feng et al. (2013) & Fewer than 2 days & One case (three subcases) & $10 \%$ \\
Method of this study & Fewer than 2 days & Three cases & $10 \%(0.1,25 \%)^{3}$ \\
\hline $\begin{array}{l}{ }^{1} \text { The time used to estimate the number of earthquake casualties. } \\
\text { (minimum, }{ }^{2} \text { The number of cases with which to evaluate the model. }{ }^{3} \text { Mean }\end{array}$
\end{tabular}

was helpful, particularly at the initial stage of earthquake relief. In the disaster areas following an earthquake, the relief supplies and rescuers were in short supply at the beginning (Li et al., 2013). This crisis usually lasts for 1 or 2 days. It is critical to decide where the emergency sites are. The fate of trapped people changes with the decision of administrators. The weighting of sites would change along with the factors, such as the arrival of additional relief supplies and rescuers, and the clearance of the roads for better accessability. Hence, it is crucial to know the change in the survival rate at each stage.

\subsection{Advantages and disadvantages of the model}

Casualty estimation helps administrators to respond properly to a crisis and to limit its impacts and losses. This study, based on the casualty mechanism, proposed a model to estimate the casualty number in a short period of time with the help of remote sensing. To achieve this model, we divided the problem into several smaller questions at each step along the timeline. The final question was solved by integrating the solutions of the smaller questions. Compared to the other methods (Table 3), the methods reported in this study had several advantages. The methods used in our model were similar to the one reported by Aghamohammadi et al. (2013). Compared to the "black box" method used by Aghamohammadi et al. (2013), we clarified the meaning of each parameter in our model. Furthermore, the parameters could be modified according to the actual situation. Using the method reported in this study, the casualties could be estimated in 2 days or fewer. We used three cases to illustrate the effectiveness of our model. The results of the three numerical simulation experiments indicate that the difference between the estimation and actual casualty counts was the least among all the methods. The characteristics of the three regions were very similar, with characteristics such as being less developed, having a high population density, and that most of the buildings were not seismically designed. If the models are to be used to estimate the number of casualties in developed countries, the parameters should be corrected according to the actual situation, or the estimated count will differ significantly from the actual number of casualties. During the literature review, we found that most of the studies in the literature only reported from their perspectives. Therefore, based on our model, we suggested a general data input standard that might be essential to the statistical part of a report regarding earthquake casualty. This study might help epidemiology researchers to make a more useful and practical report, and to allow their study to contribute more to the earthquake relief. The model could be improved when using it in developed countries. Because the data sets available to solve the model were insufficient, we could not improve the model at this point in time. From the literature reports on the earthquakes in developed countries, we found that even if the buildings were severely damaged, the casualty number was relatively low (MahueGiangreco et al., 2001). Furthermore, the proportion of casualties caused by building damage was also relatively low, and many casualties were caused by secondary disasters such as fire and traffic accidents (Osaki and Minowa, 2001). Furthermore, the amount of training received regarding earthquake relief and escape in the event of an earthquake was also relatively higher. All these factors contributed to reducing the number of casualties; however, sufficient data were not available to build a model in order to analyze the situation quantitatively.

\section{Conclusions}

The first crucial step of an earthquake relief effort is to know the number of casualties, which helps the administrators optimally distribute the relief supplies and rescuers. However, if the casualty number cannot be predicted in a short period of time, the results can only be used to evaluate the loss after the earthquake relief effort. Remote sensing has the advantages of large coverage, low cost, and a short revisit time. As the spatial resolution of satellite imagery improves, the 3-D shape of a building can be reconstructed with high accuracy to detect the damage to buildings. Therefore, this study discussed the application and prospect of high-resolution remote sensing in estimating earthquake casualties using our proposed model based on three numerical experiments. From this process, we concluded that (1) this model with a high value of adjusted $R^{2}$ and a statistically significant $p$ value could estimate the earthquake casualties in developing counties with low error, that (2) a high accuracy of predicted casualty rates required the information of the damage grade and attributes of damaged buildings, and the distribution of 
occupants in affected areas, and that (3) the changes in the casualty rates in damaged buildings were important to the design of rescue operations at macro level.

Acknowledgements. The authors thank the editor for the extensive editorial support. The authors thank the anonymous reviewers' comments on and clarification of this manuscript. The authors also thank Wenxin Niu for reviewing the manuscript, and Da Wo for polishing the language of the manuscript. This work was supported by the project on the integrated demonstration of rural remote areas disaster early warning and key rescue technology (grant no. NC2010RD0080), the National Key Technology R \& D program (grant no. 2014BAL05B06), the National Natural Science Foundation of China (grant nos. 41376178, 41325005 and 41171352, 41401489), Special Funding for the Development of Science and Technology of Shanghai Ocean University (grant no. A2-0209-14-200070), the High-tech Research and Development program of China (grant no. 2012AA12130), and the Shanghai Foundation for University Youth Scholars (grant no. ZZHY13033).

Edited by: N. Kerle

Reviewed by: two anonymous referees

\section{References}

Aghamohammadi, H., Mesgari, M., Mansourian, A., and Molaei, D.: Seismic human loss estimation for an earthquake disaster using neural network, Int. J. Environ. Sci. Tech., 10, 931-939, 2013.

Ameri, G., Massa, M., Bindi, D., D’Alema, E., Gorini, A., Luzi, L., Marzorati, S., Pacor, F., Paolucci, R., and Puglia, R.: The 6 April 2009 Mw 6.3 L'Aquila (Central Italy) Earthquake: Strong-motion Observations, Seismol. Res. Lett., 80, 951-966, 2009.

Anagnostopoulos, S. and Whitman, R.: On human loss prediction in buildings during earthquakes, Proceedings of the Sixth World Conference on Earthquake Engineering, New Delhi, India, 671676, 1977.

Aubrecht, C., Steinnocher, K., Hollaus, M., and Wagner, W.: Integrating earth observation and GIScience for high resolution spatial and functional modeling of urban land use, Computers, Environ. Urban Syst., 33, 15-25, 2009.

Aubrecht, C., Steinnocher, K., Köstl, M., Züger, J., and Loibl, W.: Spatially modeled high detail population and climate prospects for a European transect: an outlook to future patterns of vulnerability, Risk Analysis VII \& Brownfields V, 43, 219-231, 2010a.

Aubrecht, C., Yetman, G., Balk, D., and Steinnocher, K.: What is to be expected from broad-scale population data? Showcase accessibility model validation using high-resolution census information, Proceedings of AGILE, Guimarães, Portugal, 2010b.

Aubrecht, C., Freire, S., Neuhold, C., Curtis, A., and Steinnocher, K.: Introducing a temporal component in spatial vulnerability analysis, Disaster Adv., 5, 48-53, 2012.

Aubrecht, C., Özceylan, D., Steinnocher, K., and Freire, S.: Multilevel geospatial modeling of human exposure patterns and vulnerability indicators, Nat. Hazards, 68, 147-163, 2013.
Barbat, A. H., Pujades, L. G., and Lantada, N.: Seismic damage evaluation in urban areas using the capacity spectrum method: application to Barcelona, Soil Dyn. Earthq. Eng., 28, 851-865, 2008.

Benz, U. C., Hofmann, P., Willhauck, G., Lingenfelder, I., and Heynen, M.: Multi-resolution, object-oriented fuzzy analysis of remote sensing data for GIS-ready information, ISPRS J. Photogramm., 58, 239-258, 2004.

Bhaduri, B., Bright, E., Coleman, P., and Urban, M. L.: LandScan USA: a high-resolution geospatial and temporal modeling approach for population distribution and dynamics, GeoJournal, 69, 103-117, 2007.

Burchfiel, B. C., Royden, L. H., Van der Hilst, R. D., and Hager, B. H.: A geological and geophysical context for the Wenchuan earthquake of 12 May 2008, Sichuan, People's Republic of China, GSA Today, 18, 4-11, 2008.

Chen, K.: An approach to linking remotely sensed data and areal census data, Int. J. Remote Sens., 23, 37-48, 2002.

Coburn, A.: Death Tolls in Earthquakes, Workshop: Medicine in the International Decade for Natural Disaster Reduction (IDNDR): Research, Preparedness and Response for Sudden Impact Disasters in the 1990s, London, Great Britain, 21-26, 1994.

Daniell, J. E., Khazai, B., and Wenzel, F.: Uncovering the 2010 Haiti earthquake death toll, Nat. Hazards Earth Syst. Sci. Discuss., 1, 1913-1942, doi:10.5194/nhessd-1-1913-2013, 2013.

Dobson, J. E., Bright, E. A., Coleman, P. R., Durfee, R. C., and Worley, B. A.: LandScan: a global population database for estimating populations at risk, Photogramm. Eng. Rem. S., 66, 849-857, 2000.

Feng, T., Hong, Z., Wu, H., Fu, Q., Wang, C., Jiang, C., and Tong, X.: Estimation of earthquake casualties using highresolution remote sensing: a case study of Dujiangyan city in the May 2008 Wenchuan earthquake, Nat. Hazards, 69, 1577-1595, 2013.

Freire, S. and Aubrecht, C.: Integrating population dynamics into mapping human exposure to seismic hazard, Nat. Hazards Earth Syst. Sci., 12, 3533-3543, doi:10.5194/nhess-12-3533-2012, 2012.

Gamba, P. and Casciati, F.: GIS and image understanding for nearreal-time earthquake damage assessment, Photogramm. Eng. Rem. S., 64, 987-994, 1998.

Gerke, M. and Kerle, N.: Automatic structural seismic damage assessment with airborne oblique pictometry imagery, Photogramm. Eng. Rem. S., 77, 885-898, 2011.

Guo, H. D., Zhang, B., Lei, L. P., Zhang, L., and Chen, Y.: Spatial distribution and inducement of collapsed buildings in Yushu earthquake based on remote sensing analysis, Sci. China Earth Sci., 53, 794-796, 2010.

Gutiérrez, E., Taucer, F., De Groeve, T., Al-Khudhairy, D., and Zaldivar, J.: Analysis of worldwide earthquake mortality using multivariate demographic and seismic data, Am. J. Epidemiol., 161, 1151-1158, 2005.

Hay, S., Noor, A., Nelson, A., and Tatem, A.: The accuracy of human population maps for public health application, Trop. Med. Int. Health, 10, 1073-1086, 2005.

Hisada, Y., Shibayama, A., and Ghayamghamian, M. R.: Building damage and seismic intensity in Bam City from the 2003 Iran, Bam, Earthquake, Bull. Earthquake Res. Inst., Univ. Tokyo, 79, 81-94, 2005. 
Huang, L. P., Oguni, K., and Hori, M.: Image Analysis of Measuring Building Configuration for Seismic Damage Estimation, Nat. Hazards Rev., 14, 1-10, 2013.

Jaiswal, K., Wald, D., Earle, P., Porter, K., and Hearne, M.: Earthquake casualty models within the USGS Prompt Assessment of Global Earthquakes for Response (PAGER) system, in: Human Casualties in Earthquakes, Springer, Netherlands, 83-94, 2011.

Kenny, C.: Disaster risk reduction in developing countries: costs, benefits and institutions, Disasters, 36, 559-588, 2012.

Kerle, N.: Satellite-based damage mapping following the 2006 Indonesia earthquake - How accurate was it?, Int. J. Appl. Earth. Obs., 12, 466-476, 2010.

Kerle, N. and Hoffman, R. R.: Collaborative damage mapping for emergency response: the role of Cognitive Systems Engineering, Nat. Hazards Earth Syst. Sci., 13, 97-113, doi:10.5194/nhess-1397-2013, 2013.

Kuwata, Y., Takada, S., and Bastami, M.: Building damage and human casualties during the Bam-Iran earthquake, Asian J. Civil Eng., 6, 1-19, 2005.

Lay, T., Ammon, C., Kanamori, H., Koper, K., Sufri, O., and Hutko, A.: Teleseismic inversion for rupture process of the 27 February 2010 Chile $\left(\mathrm{M}_{\mathrm{w}}\right.$ 8.8) earthquake, Geophys. Res. Lett., 37, L13301, doi:10.1029/2010GL043379, 2010.

Li, D., Zeng, L., Chen, N., Shan, J., Liu, L., Fan, Y., and Li, W.: A framework design for the Chinese National Disaster Reduction System of Systems (CNDRSS), Int. J. Digit. Earth, 7, 68-87, 2013.

Lu, L., Guo, H., and Corbane, C.: Building Damage Assessment with VHR Images and Comparative Analysis for Yushu Earthquake, China, Disaster Adv., 6, 37-44, 2013.

Ma, R.: DEM generation and building detection from Lidar data, Photogramm. Eng. Rem. S., 71, 847-854, 2005.

Macintyre, A. G., Barbera, J. A., and Petinaux, B. P.: Survival interval in earthquake entrapments: research findings reinforced during the 2010 Haiti earthquake response, Disaster Med. Publ. Health Prep., 5, 13-22, 2011.

Mahue-Giangreco, M., Mack, W., Seligson, H., and Bourque, L. B.: Risk factors associated with moderate and serious injuries attributable to the 1994 Northridge earthquake, Los Angeles, California, Ann. Epidemiol., 11, 347-357, 2001.

Mimura, N., Yasuhara, K., Kawagoe, S., Yokoki, H., and Kazama, S.: Damage from the Great East Japan Earthquake and Tsunami - A quick report, Mitig. Adapt. Strat. Gl., 16, 803-818, 2011.

Ni, S., Wang, W., and Li, L.: The April 14th, 2010 Yushu earthquake, a devastating earthquake with foreshocks, Sci. China Earth Sci., 53, 791-793, 2010.

Osaki, Y. and Minowa, M.: Factors associated with earthquake deaths in the great Hanshin-Awaji earthquake, 1995, Ann. Epidemiol., 153, 153-156, 2001.

Peek-Asa, C., Kraus, J. F., Bourque, L. B., Vimalachandra, D., Yu, J., and Abrams, J.: Fatal and hospitalized injuries resulting from the 1994 Northridge earthquake, Int. J. Epidemiol., 27, 459-465, 1998.

Petal, M.: Earthquake casualties research and public education, in: Human Casualties in Earthquakes, Springer, Netherlands, 25-50, 2011.
Porter, K., Jaiswal, K., Wald, D., Earle, P., and Hearne, M.: Fatality models for the US Geological Survey's Prompt Assessment of Global Earthquake for Response (PAGER) system, Paper S04009, 14th World Conference of Earthquake Engineering, Beijing, 2008 ,

Saito, K., Spence, R. J., Going, C., and Markus, M.: Using highresolution satellite images for post-earthquake building damage assessment: a study following the 26 January 2001 Gujarat earthquake, Earthq. Spectra, 20, 145-169, 2004.

Shalaby, A. and Tateishi, R.: Remote sensing and GIS for mapping and monitoring land cover and land-use changes in the Northwestern coastal zone of Egypt, Appl. Geogr., 27, 28-41, 2007.

Shiono, K.: Interpretation of published data of the 1976 Tangshan, China Earthquake for the determination of a fatality rate function, Proceedings - Japan Society Of Civil Engineers, Dotoku Gakkai, 25-33, 1995.

Stone, R.: An unpredictably violent fault, Science, 320, 1578-1580, 2008.

Sutton, P., Roberts, D., Elvidge, C., and Baugh, K.: Census from Heaven: an estimate of the global human population using nighttime satellite imagery, Int. J. Remote Sens., 22, 3061-3076, 2001.

Tack, F., Buyuksalih, G., and Goossens, R.: 3D building reconstruction based on given ground plan information and surface models extracted from spaceborne imagery, ISPRS J. Photogramm., 67, 52-64, doi:10.1016/j.isprsjprs.2011.10.003, 2012.

Tang, B. and Zhang, L.: Ya' an earthquake, Lancet, 381, 1984-1985, 2013.

Tao, C. V., Hu, Y., and Jiang, W.: Photogrammetric exploitation of IKONOS imagery for mapping applications, Int. J. Remote. Sens., 25, 2833-2853, 2004.

Teeuw, R. M., Leidig, M., Saunders, C., and Morris, N.: Free or lowcost geoinformatics for disaster management: Uses and availability issues, Environ. Hazards-Uk, 12, 112-131, 2013.

Tiedemann, H.: Casualties as a function of building quality and earthquake intensity, Proceedings of the international workshop on earthquake injury epidemiology for mitigation and response, Maryland, USA, 10-12, 1989

Tong, X. H., Hong, Z. H., Liu, S. J., Zhang, X., Xie, H., Li, Z. Y., Yang, S. L., Wang, W. A., and Bao, F.: Building-damage detection using pre- and post-seismic high-resolution satellite stereo imagery: A case study of the May 2008 Wenchuan earthquake, ISPRS J. Photogramm., 68, 13-27, 2012.

Tong, X. H., Lin, X. F., Feng, T. T., Xie, H., Liu, S. J., Hong, Z. H., and Chen, P.: Use of shadows for detection of earthquakeinduced collapsed buildings in high-resolution satellite imagery, ISPRS J. Photogramm., 79, 53-67, 2013.

Turker, M. and Cetinkaya, B.: Automatic detection of earthquakedamaged buildings using DEMs created from pre- and postearthquake stereo aerial photographs, Int. J. Remote Sens., 26, 823-832, 2005.

Turker, M. and Sumer, E.: Building-based damage detection due to earthquake using the watershed segmentation of the post-event aerial images, Int. J. Remote Sens., 29, 3073-3089, 2008.

USGS: Magnitude 6.6 - Southeastern Iran, Earthquake Hazards Program, http://web.archive.org/web/20080922155753/http: //earthquake.usgs.gov/eqcenter/eqinthenews/2003/uscvad/ (last access: 8 October 2013), 2003. 
Wang, X., Dou, A., Sun, G., Ding, X., Wang, L., and Yuan, X.: Intensity Assessment of the 2010 Yushu Ms 7.1 Earthquake Based on Synthetic Seismic Damage Index, Earthquake, 33, 110, 2013.

Wyss, M.: Real-time prediction of earthquake casualties, Disasters and society - from hazard assessment to risk reduction, Logos, Karlsruhe, 165-173, 2004.

Wyss, M. and Trendafiloski, G.: Trends in the casualty ratio of injured to fatalities in earthquakes, in: Human Casualties in Earthquakes, Springer, Netherlands, 267-274, 2011.

Xu, C., Liu, A., and Wen, Z.: Study on casualties of Dujiangyan City in the Wenchuan earthquake, J. Earthq. Eng. Eng. Vibrat., 32, 182-188, 2012.

Yamazaki, F., Nishimura, A., and Ueno, Y.: Estimation of human casualties due to urban earthquakes, Proceedings of the 11th World Conference on Earthquake Engineering, Acapulco, Mexico, 1996.
Yamazaki, F., Yano, Y., and Matsuoka, M.: Visual damage interpretation of buildings in Bam city using quickbird images following the 2003 Bam, iran, earthquake, Earthq. Spectra, 21, 329-336, 2005.

Yano, Y., Yamazaki, F., Matsuoka, M., and Vu, T. T.: Building damage detection of the 2003 Bam, Iran earthquake using QuickBird images, Proceedings of the 25th Asian Conference on Remote Sensing, Chiang Mai, Thailand, 618-623, 2004.

Yu, S., Zhang, L., and Zhao, Z.: Study on Assessment Method of Buried People after Destructive Earthquake, LISBOA 2013, Lisbon, Portugal, 2013.

Zuccaro, G. and Cacace, F.: Seismic Casualty Evaluation: The Italian Model, an Application to the L'Aquila 2009 Event, in: Human Casualties in Earthquakes, Springer, Netherlands, 171-184, 2011. 